\title{
Effects of limonene on ruminal Fusobacterium necrophorum concentrations, fermentation, and lysine degradation in cattle ${ }^{1}$
}

\author{
S. Saed Samii, * N. Wallace, $\uparrow$ T. G. Nagaraja, $\uparrow$

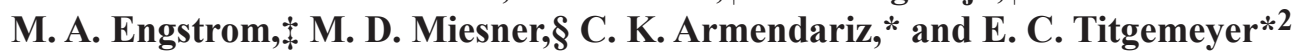 \\ *Department of Animal Sciences and Industry, Kansas State University, Manhattan 66506; \\ $\dagger$ Department of Diagnostic Medicine and Pathobiology, Kansas State University, Manhattan 66506; \$DSM Nutritional \\ Products, Inc., Parsippany, NJ 07054; and §Department of Clinical Sciences, Kansas State University, Manhattan 66506
}

\begin{abstract}
Previous in vitro data showed that Fusobacterium necrophorum was inhibited by limonene. We further evaluated effects of limonene on growth of $F$. necrophorum in vitro as well as on ruminal concentrations of $F$. necrophorum in vivo. With in vitro cultivation in anaerobic brain-heart infusion broth, limonene decreased growth of $F$. necrophorum. Thymol also reduced growth of F. necrophorum, but it was less effective than limonene. Tylosin effectively reduced growth of $F$. necrophorum in vitro. Although the response over fermentation times and concentrations of antimicrobials differed somewhat between tylosin and limonene, the 2 antimicrobial agents yielded similar inhibitory effects on growth of $F$. necrophorum at concentrations ranging from 6 to $24 \mathrm{mg} / \mathrm{L}$. The effects of limonene on ruminal $F$. necrophorum concentration in vivo were tested in 7 ruminally cannulated heifers $(225 \mathrm{~kg}$ initial $\mathrm{BW}$ ) used in a $7 \times 4$ Youden square design. Treatments included: 1) control, 2) limonene at $10 \mathrm{mg} / \mathrm{kg} \operatorname{diet} \mathrm{DM}$, 3) limonene at $20 \mathrm{mg} / \mathrm{kg}$ diet DM, 4) limonene at 40 $\mathrm{mg} / \mathrm{kg}$ diet DM, 5) limonene at $80 \mathrm{mg} / \mathrm{kg} \operatorname{diet} \mathrm{DM}, 6$ ) CRINA-L (a blend of essential oil components) at 180 $\mathrm{mg} / \mathrm{kg}$ diet $\mathrm{DM}$, and 7) tylosin at $12 \mathrm{mg} / \mathrm{kg}$ diet DM. Each period included $11 \mathrm{~d}$ with $10 \mathrm{~d}$ washouts between
\end{abstract}

periods. Samples of ruminal contents were collected before treatment initiation and after 4,7 , and $10 \mathrm{~d}$ of treatment for measuring $F$. necrophorum by the most probable number method using selective culture medium. Limonene linearly decreased $(P=0.03)$ ruminal $F$. necrophorum concentration, with the lowest concentration achieved with $40 \mathrm{mg}$ of limonene $/ \mathrm{kg}$ dietary DM. Limonene tended $(P \leq 0.07)$ to linearly reduce ruminal molar proportions of propionate and valerate while tending to linearly increase $(P \leq 0.10)$ those of butyrate and 2-methyl butyrate. Limonene did not affect ruminal $\mathrm{NH}_{3}$ concentrations or degradation rates of lysine. Neither CRINA-L $(P=0.52)$ nor tylosin $(P=$ $0.19)$ affected ruminal $F$. necrophorum concentrations. CRINA-L significantly decreased ruminal concentrations of $\mathrm{NH}_{3}$ and molar proportions of 3-methyl butyrate, whereas tylosin significantly decreased molar proportions of propionate while increasing those of butyrate and tending to increase those of acetate. Limonene supplementation reduced ruminal concentrations of $F$. necrophorum suggesting that it may have the potential to reduce the prevalence of liver abscesses, although further research is needed to assess the effect of limonene in feedlot cattle.

Key words: cattle, essential oil, Fusobacterium necrophorum, limonene, rumen

\section{INTRODUCTION}

\footnotetext{
${ }^{1}$ Contribution 16-256-J from the Kansas Agricultural Experiment Station, Manhattan. DSM Nutritional Products, Inc. provided funding to support this research. Authors extend appreciation to Joanna Wilson for help in working with the cattle.

${ }^{2}$ Corresponding author: etitgeme@ksu.edu

Received March 10, 2016.

Accepted May 18, 2016.
}

Liver abscesses are a major economic problem in the feedlot industry, and the prevalence is associated with the feeding of grain-based diets (Nagaraja and Lechtenberg, 2007). Fusobacterium necrophorum (FN) is the main pathogenic bacterium that causes liver abscesses and is also a normal inhabitant of the rumen (Tadepalli et al., 2009). When FN penetrates the 
ruminal wall and gains access to the portal blood, it can reach the liver and cause abscesses (Jensen et al., 1954; Scanlan and Hathcock, 1983; Tadepalli et al., 2009).

Tylosin, a macrolide antibiotic, is used commonly in feedlots to reduce prevalence of liver abscesses (Nagaraja et al., 1996). Although tylosin reduces liver abscesses, it raises public concern as an antibiotic belonging to a medically important class; therefore, alternatives that would satisfy the public view while meeting the needs of the beef industry would have value. Essential oils and their major components, such as thymol and eugenol, have been investigated as an alternative to antibiotics (Dorman and Deans, 2000; McIntosh et al., 2003) because of their antimicrobial activity (Helander et al., 1998; Calsamiglia et al., 2007). Limonene is an organic compound contained in lemons, oranges, and grapefruit (Castillejos et al., 2006) and has been shown to have activity mainly against Gram-negative bacteria (Dorman and Deans, 2000). Elwakeel et al. (2013) studied the effects of a number of essential oil components on FN growth in vitro, and they observed that limonene at 20 or $100 \mathrm{mg} / \mathrm{L}$ and thymol at $100 \mathrm{mg} / \mathrm{L}$ were effective in decreasing growth of the 2 subspecies of $\mathrm{FN}$, ssp. necrophorum (FNsN) and ssp. funduliforme (FNsF).

Our objective was to further evaluate the effects of limonene, thymol, and tylosin in vitro on growth of FN and the effects of limonene, tylosin, and CRINA-L (a blend of essential oil components) in vivo on ruminal concentrations of FN, fermentation, and lysine degradation.

\section{MATERIALS AND METHODS}

\section{Experiment 1: Effects of Limonene and Thymol on In Vitro Growth of FN}

This experiment evaluated concentrations of limonene and thymol, included at $0,1,5,10,20,40,70$, and $100 \mu \mathrm{g} / \mathrm{mL}$ of the culture medium on growth of FN. The concentrations of limonene and thymol were based on ruminal concentrations that might be achieved with a daily dose of $1 \mathrm{~g}$ of the compounds to cattle and on data of Elwakeel et al. (2013), which demonstrated that $20 \mu \mathrm{g} / \mathrm{mL}$ of limonene or $100 \mu \mathrm{g} /$ $\mathrm{mL}$ of thymol was effective in reducing growth of FN.

This experiment utilized 2 replicates conducted on different days. The first replicate used 5 strains of FN (1 strain of FNsN [A29] and 4 strains of FNsF [B33, B34, B35, and B36]). Seven cultures of FN strains were initially cultured, but 2 cultures did not grow enough to justify their use as inoculum. The second replicate used 8 strains of FN (4 strains of FNsN [A29, A16, A18, and A13] and 4 strains of FNsF [B33, B34, B37, and B38]). For the second replicate, 12 strains were initially cul- tured, and the 4 most rapidly growing cultures of FNsN and the 4 most rapidly growing cultures of FNsF were used as inoculum sources. The FNsN and FNsF strains were all of ruminal origin (Tan et al., 1994a).

Each strain was tested in duplicate tubes for each concentration of limonene and thymol. Strains were cultivated in Hungate tubes containing $10 \mathrm{~mL}$ of prereduced (with $0.05 \%$ cysteine- $\mathrm{HCl}$ ) and anaerobically sterilized brain heart infusion broth (PRAS-BHI; Becton Dickinson, Sparks, MD). The compounds were dissolved in methanol, and $100 \mu \mathrm{L}$ of solutions were pipetted into tubes just prior to inoculation to provide the appropriate concentrations. Control tubes received $100 \mu \mathrm{L}$ of methanol. Tubes were inoculated with $0.1 \mathrm{~mL}$ of 6-h cultures of FN strains prepared as described below. Duplicate tubes were incubated for $48 \mathrm{~h}$ at $39^{\circ} \mathrm{C}$. Growth was measured by recording absorbance at 600 $\mathrm{nm}$ at 24 and $48 \mathrm{~h}$; however, because absorbance did not increase between 24 and 48 h only the 24 -h values were analyzed. An extra control tube was inoculated with each strain and was subsequently plated after $24 \mathrm{~h}$ to verify that cultures were pure.

Preparation of FN Cultures. The stored cultures were streaked on blood agar plates (Remel Inc., Lenexa, $\mathrm{KS}$ ) and incubated for $48 \mathrm{~h}$ at $39^{\circ} \mathrm{C}$ in an anaerobic glove box $\left(10 \% \mathrm{H}_{2}, 10 \% \mathrm{CO}_{2}, 80 \% \mathrm{~N}_{2}\right.$; Forma Scientific Inc., Marietta, $\mathrm{OH})$. The species and subspecies of strains were reconfirmed with a commercial identification kit (RapID ANA II System; Innovative Diagnostic Systems Inc., Atlanta, GA; Tan et al., 1994a). A single colony from each plate was inoculated into $10 \mathrm{~mL}$ of PRAS-BHI broth and incubated at $39^{\circ} \mathrm{C}$ for $16 \mathrm{~h}$. Then, $100 \mu \mathrm{L}$ of the culture was inoculated into $10 \mathrm{~mL}$ of PRAS-BHI broth and incubated at $39^{\circ} \mathrm{C}$ for approximately $6 \mathrm{~h}$ and used as inoculum. Absorbance of inoculum at $600 \mathrm{~nm}$ averaged 0.70 for the first replicate and 0.76 for the second replicate. The inoculum generally contained 1 to $5 \times 10^{9}$ $\mathrm{cfu} / \mathrm{mL}$. The purity of the inocula was verified by microscopic examination of Gram-stained smears.

Data were analyzed by ANOVA using the Mixed Procedure of SAS 9.3 (SAS Inst. Inc., Cary, NC) with a model including: FN subspecies (FNsN vs. FNsF), antimicrobial treatment (various concentrations of limonene and thymol), and their interaction. Random effects included: replicate, strain nested within subspecies, and replicate $\times$ antimicrobial treatment $\times$ strain nested within subspecies. This last random effect was included to treat the replicate tubes within each replicate fermentation as technical replicates rather than as experimental units. Effects of limonene and thymol concentrations as well as their interactions with FN subspecies were evaluated using contrasts for the linear, quadratic, and cubic effects of each compound; contrast coefficients were calculated for unequally spaced treatments using 
the IML Procedure of SAS. A direct comparison of limonene to thymol was also conducted with a contrast that compared the average of all concentrations of limonene to the average of all concentrations of thymol.

\section{Experiment 2: Interactions between Limonene and Thymol on In Vitro Growth of FN}

This experiment was conducted to determine if there were additive effects of limonene and thymol on the growth of FN in vitro. The trial was conducted concurrently with Exp. 1 using the same methods and also using some of the treatments and data from Exp. 1. Treatments were arranged as a $4 \times 4$ factorial and included 4 concentrations of limonene $(0,5,10$, and $20 \mathrm{mg} / \mathrm{L})$ and 4 concentrations of thymol $(0,5,10$, and $20 \mathrm{mg} / \mathrm{L})$. Similar to Exp. 1, only the 24-h growth data were used.

Data were analyzed by ANOVA using the Mixed Procedure of SAS 9.3 with a model including: subspecies (FNsN vs. FNsF), thymol concentration, limonene concentration, and all possible combinations of those 3 factors. Random effects included: replicate, strain nested within subspecies, and the interaction of replicate $\times$ thymol $\times$ limonene $\times$ strain nested within subspecies. This last random effect was included to treat the duplicate tubes within each replicate as technical replicates rather than as experimental units. Effects of limonene and thymol concentrations, as well as their interactions with each other and with FN subspecies, were tested using linear, quadratic, and cubic contrasts for limonene and thymol concentrations; contrast coefficients were calculated for unequally spaced treatments using the IML Procedure of SAS.

\section{Experiment 3: Effects of Limonene and Tylosin on In Vitro Growth of FN}

This experiment was conducted to determine the sensitivity of FN growth to limonene and tylosin in vitro. Eleven treatments were evaluated, including a control with no additive, 5 concentrations of limonene $(6$, $12,24,48$, and $96 \mu \mathrm{g} / \mathrm{mL}$ ), and 5 concentrations of tylosin $(1.5,3,6,12$, and $24 \mu \mathrm{g} / \mathrm{mL})$. The concentrations of limonene were based on data from Exp. 1, and those for tylosin were based on previously documented minimum inhibitory concentration (MIC) of 10 to $25 \mu \mathrm{g} /$ mL (Tan et al., 1994a; Nagaraja et al., 1999a; Elwakeel et al., 2013). Treatments were evaluated for their ability to inhibit growth of 8 strains of FN (FNsN: A16, A21, A27, and A29; FNsF: B33, B34, B36, and B38).

Each of the $8 \mathrm{FN}$ strains was tested in duplicate tubes for each of the 11 treatments (176 total tubes), using methodology described for Exp. 1, except growth (absorbance at $600 \mathrm{~nm}$ ) was measured at 12 and $24 \mathrm{~h}$.
Table 1. Composition of diets fed to heifers in Exp. 4 (\% of DM)

\begin{tabular}{lcc}
\hline \hline Ingredient & 6 heifers & 1 heifer \\
\hline Alfalfa hay & 28.3 & 46.2 \\
Molasses, cane & 2.7 & 2.0 \\
Dry rolled corn & 59.4 & 44.5 \\
Solvent soybean meal & 8.2 & 6.1 \\
Limestone, 38\% Ca & 1.4 & 1.0 \\
Vitamins/Minerals & $0.12^{1}$ & $0.09^{2}$ \\
\hline
\end{tabular}

${ }^{1}$ Provided (per kg diet DM): 1,906 IU vitamin A, 190 IU vitamin D, 36 IU vitamin E, $49 \mathrm{mg} \mathrm{Mn}, 49 \mathrm{mg} \mathrm{Zn,} 8 \mathrm{mg} \mathrm{Cu}, 0.11 \mathrm{mg} \mathrm{Co}, 0.52 \mathrm{mg} \mathrm{I}$, and $0.1 \mathrm{mg} \mathrm{Se}$.

${ }^{2}$ Provided (per kg diet DM): 1,429 IU vitamin A, 142 IU vitamin D, 27 IU vitamin E, $37 \mathrm{mg} \mathrm{Mn}, 37 \mathrm{mg} \mathrm{Zn}, 6 \mathrm{mg} \mathrm{Cu}, 0.08 \mathrm{mg} \mathrm{Co}, 0.39 \mathrm{mg} \mathrm{I}$, and $0.08 \mathrm{mg} \mathrm{Se}$.

Data were analyzed using the Mixed Procedure of SAS 9.3 with a model including: FN subspecies (FNsN vs. FNsF), antimicrobial treatment (various concentrations of limonene and tylosin), the interaction between FN subspecies and antimicrobial treatment, time (12 vs. $24 \mathrm{~h}$, treated as a repeated measure), and the interactions of time with the other fixed effects. Random effects included: strain nested within subspecies and the interaction of antimicrobial treatment with strain nested within subspecies. The latter random effect was included to treat the duplicate tubes within each replicate fermentation as technical replicates rather than as experimental units. Effects of limonene and tylosin concentrations as well as their interactions with FN subspecies were evaluated using contrasts for the linear, quadratic, and cubic effects of each compound; contrast coefficients were calculated for unequally spaced treatments using the IML Procedure of SAS. Direct comparisons of limonene to tylosin at concentrations of 6,12 , and $24 \mathrm{mg} / \mathrm{L}$ were made with pair-wise contrasts.

\section{Experiment 4: Effect of Limonene, Tylosin, and CRINA-L on In Vivo Ruminal Concentrations of FN, Fermentation, and Lysine Degradation}

Animals and Treatments. The Kansas State University Institutional Animal Care and Use Committee approved procedures involving animal use. Seven ruminally cannulated Holstein heifers ( $210 \pm 10 \mathrm{~d}$ of age, and approximately $225 \mathrm{~kg}$ initial BW) were used in a $7 \times 4$ Youden square design ( 7 treatments, 7 heifers, 4 periods) to evaluate the effect of different levels of limonene on ruminal FN concentrations. Treatments were allocated so, in periods 2 through 4 , each treatment followed 3 different treatments. Diet composition is presented in Table 1. All heifers were fed $5 \mathrm{~kg}$ of diet (as-fed) daily, with equal amounts provided at 12 -h intervals. One heifer received a diet with a higher concentration of al- 
falfa because it would not adequately consume the other diet. Treatments were mixed thoroughly into diets before feeding and included: 1) control (nothing added); 2) $10 \mathrm{mg}$ limonene/kg diet DM; 3) $20 \mathrm{mg}$ limonene $/ \mathrm{kg}$ diet DM; 4) $40 \mathrm{mg}$ limonene/kg diet DM; 5) $80 \mathrm{mg}$ limonene/ $\mathrm{kg}$ diet DM); 6) 12 mg tylosin/kg DM (Tylan 40; Elanco, Animal Health, Indianapolis, IN); and 7) $180 \mathrm{mg}$ CRINA-L Ruminants/kg DM (DSM Nutritional Products AG; Kaiseraugst, Switzerland). The limonene was provided as a product containing 20\% D-limonene added to a carrier (DSM Nutritional Products). The CRINA-L was a mixture of essential oil components formulated from CRINA Ruminants by increasing D-limonene in the product to $11 \%$ of the final weight; thus, the CRINA$\mathrm{L}$ treatment provided $20 \mathrm{mg}$ limonene $/ \mathrm{kg}$ diet DM.

Heifers were housed in tie-stalls in a controlled environment room $\left(22^{\circ} \mathrm{C}\right)$ with $16 \mathrm{~h}$ of lighting daily. Each period lasted $11 \mathrm{~d}$ with $10 \mathrm{~d}$ of washout between periods. One observation for the CRINA-L treatment was missed from the final period due to issues not related to treatment.

Sample Collection and Analysis. On d 0 (prior to initiation of treatments) and on $\mathrm{d} 4,7$, and 10 of each period, $100 \mathrm{~mL}$ of ruminal fluid was collected before the morning feeding. Ruminal fluid $\mathrm{pH}$ was measured by $\mathrm{pH}$ meter (ATI, Orion, Boston, MA), and then samples were immediately strained through 4 layers of cheesecloth into a 50-mL conical bottom tube and transferred to the lab for enumeration of FN. The procedure of Tan et al. (1994b) was used for enumeration of $\mathrm{FN}$ with minor modification to the selective medium; $\left(\mathrm{NH}_{4}\right)_{2} \mathrm{SO}_{4}$ concentration was $0.45 \mathrm{~g} / \mathrm{L}$ and $\mathrm{MgSO}_{4} \cdot 7 \mathrm{H}_{2} \mathrm{O}$ was $0.045 \mathrm{~g} / \mathrm{L}$. The most probable number (MPN) method was used to determine the FN concentrations following growth in selective medium and positive identification of indole production with Kovac's reagent (Sigma, St Louis, MO). The MPN were conducted in 96-well plates and were calculated from 8 rows of serial dilutions for each sample. In the first period, we used $0.1 \mathrm{~mL}$ of ruminal fluid in the first column and conducted 10 -fold serial dilutions. In the remaining 3 periods, we used $0.2 \mathrm{~mL}$ of ruminal fluid in the first column and conducted fivefold serial dilutions. The change in protocol was made because there were no positive wells at higher dilutions in the first period, and the lower dilutions allowed for better sensitivity.

On d 10, ruminal fluid samples were collected at 2, 4, 6, 8, and $10 \mathrm{~h}$ after the morning feeding. From the fluid collected prior to feeding as well as at all time points after feeding, $\mathrm{pH}$ was measured and then $1 \mathrm{~mL}$ of rumen fluid strained through 4 layers of cheesecloth was mixed with $0.25 \mathrm{~mL}$ of $25 \%$ (wt/vol) meta-phosphoric acid and stored frozen for later analysis of $\mathrm{NH}_{3}$ and organic acids. In addition, $10 \mathrm{~mL}$ of strained rumen fluid was mixed with $0.5 \mathrm{~mL}$ of $70 \%$ (wt/wt) perchloric acid and stored frozen for later peptide analysis.

On d 11, a 1-L solution of Cr-EDTA $(2.83 \mathrm{~g} \mathrm{Cr})$ containing $38.2 \mathrm{~g} \mathrm{~L}-$ lysine- $\mathrm{HCl}$ (30 g lysine) was dosed through the ruminal cannula just before the morning feeding. At 3, 6, 9, and $12 \mathrm{~h}$ after dosing, $100 \mathrm{~mL}$ of ruminal fluid was collected and strained through 4 layers of cheesecloth. Strained ruminal fluid was stored frozen for later $\mathrm{Cr}$ analysis. In addition, $1 \mathrm{~mL}$ of strained rumen fluid was mixed with $0.25 \mathrm{~mL}$ of $25 \%$ (wt/vol) meta-phosphoric acid and then stored frozen for $\mathrm{NH}_{3}$ analysis. A sample of strained ruminal fluid $(0.75 \mathrm{~mL})$ was mixed with $0.75 \mathrm{~mL}$ SERAPREP (Pickering Laboratories, Mountain View, CA) containing $1 \mathrm{~m} M$ norleucine, vortexed, and stored frozen for later analysis of lysine. Data from d 11 were used to estimate ruminal lysine disappearance rate, liquid dilution rate, and lysine degradation rate (Binnerts et al., 1968; Merchen, 1988).

Laboratory Analyses. Thawed ruminal samples were prepared for analysis by centrifuging at $17,000 \times g$ for $15 \mathrm{~min}$ at $4^{\circ} \mathrm{C}$ and collecting the supernatant. Concentrations of VFA and lactate were measured using GLC with flame-ionization detection (column: $2 \mathrm{~m} \times 2 \mathrm{~mm}$ i.d. Carbopak B-DA [Supelco, Bellefonte, PA], injection temperature $200^{\circ} \mathrm{C}$, detector temperature $200^{\circ} \mathrm{C}$, oven temperature $175^{\circ} \mathrm{C}$, flow rate: $24 \mathrm{~mL} / \mathrm{min}$ of $\mathrm{N}_{2}$ ). The procedure of Broderick and Kang (1980) was used to measure $\mathrm{NH}_{3}$ concentrations. Automated trinitrobenzene sulfonic acid analysis (Palmer and Peters, 1969) was used to determine concentrations of ruminal $\alpha$-amino $\mathrm{N}$ before and after acid hydrolysis; peptide $\mathrm{N}$ was calculated as the increase in $\alpha$-amino $\mathrm{N}$ on hydrolysis (Ives et al., 2002). For analysis of lysine, samples were thawed and centrifuged $\left(13,800 \times g ; 10 \mathrm{~min} ; 4^{\circ} \mathrm{C}\right)$ with the supernatant refrozen. Samples were analyzed for lysine using cation exchange HPLC with measurement by fluorimetry after postcolumn o-phthalaldehyde derivitization (Beckman System Gold; Beckman, Palo Alto, CA). Concentrations of $\mathrm{Cr}$ were measured by atomic absorption spectrophotometry.

Calculations and Statistical Analyses. The MPN data were $\log 10$ transformed prior to analysis to normalize the data. The ANOVA was conducted using the Mixed Procedure of SAS. The model included fixed effects of period, treatment, day, and treatment $\times$ day. The log-transformed MPN from Day 0 was included as a covariate. Heifer was included as a random effect. Day was considered as a repeated variable within each cell, and the covariance structure was compound symmetry. The autoregressive and unstructured covariance structures were also considered, but compound symmetry led to smaller AIC. The denominator degrees of freedom were based on the Kenwood-Rogers method. Means were separated with contrasts for 1) control vs. tylosin, 2) control vs. CRINA-L, and 3) linear, 4) 
quadratic, and 5) cubic effects of limonene based on unequally spaced treatments. Outliers were removed when $\mid$ studentized residuals $\mid>3$. For MPN, there were 2 outliers ( 7 and 10 for a heifer receiving CRINA-L). The $\mathrm{pH}$ data collected at the time of sampling for FN were analyzed the same as for the MPN data.

Data for ruminal characteristics from d 10 were analyzed similarly to that for MPN, except time after feeding, rather than day, was the repeated measure. For all ruminal characteristics, the covariance structure used was compound symmetry, because compound symmetry led to lower AIC for more variables than autoregressive and the unstructured option did not allow the model to converge for all characteristics. With the exception of molar percentage of acetate, no treatment $\times$ time interactions were observed; for acetate, evaluation of the patterns over time suggested that this interaction was trivial. Thus, only main effects of treatment are presented. Means were separated using the contrasts described above. Concentrations of lactate were included in the calculation of total organic acids, but statistical analysis was not conducted for lactate because $86 \%$ of observations were below detection limits, only $7 \%$ were $>1 \mathrm{~m} M$, and none were $>5 \mathrm{~m} M$.

Lysine degradation on d 11 was calculated and analyzed as follows. Using the NLIN Procedure of SAS, ruminal $\mathrm{Cr}$ concentrations for each heifer in each period were fit to the model: $\mathrm{Cr}$ concentration $=\mathrm{Cr}$ concentration at dosing $\times \mathrm{e}^{-(\mathrm{kp} \times \mathrm{t})}$, where $\mathrm{kp}$ is the liquid passage rate and $\mathrm{t}=$ time after dosing. The model-calculated concentration at dosing was used to calculate ruminal liquid volume as: $\mathrm{Cr}$ dose ( $\mathrm{g}$ )/Cr concentration at dosing. Ruminal lysine concentrations at dosing, which were included in the data set for calculating lysine disappearance rates, were calculated as: lysine dose/ruminal liquid volume. With the NLIN Procedure of SAS, ruminal lysine concentrations were fit to the model: Lysine concentration $=$ lysine concentration at dosing (model calculated) $\times \mathrm{e}^{-}$ $(\mathrm{kdis} \times \mathrm{t})$, where kdis is the lysine disappearance rate and $\mathrm{t}=$ time after dosing. Lysine degradation rate was calculated as lysine disappearance rate minus liquid passage rate. Analysis of variance with the Mixed Procedure of SAS was then used to analyze the parameter estimates; the model included period and treatment as fixed effects, and heifer was included as a random effect. Means were separated using the contrasts described above.

\section{RESULTS AND DISCUSSION}

\section{Experiment 1: Effects of Limonene and Thymol on In Vitro Growth of FN}

Figure 1 shows the effects of limonene and thymol on FN growth in vitro. Limonene inclusion in the culture medium led to linear and quadratic decreases in FN
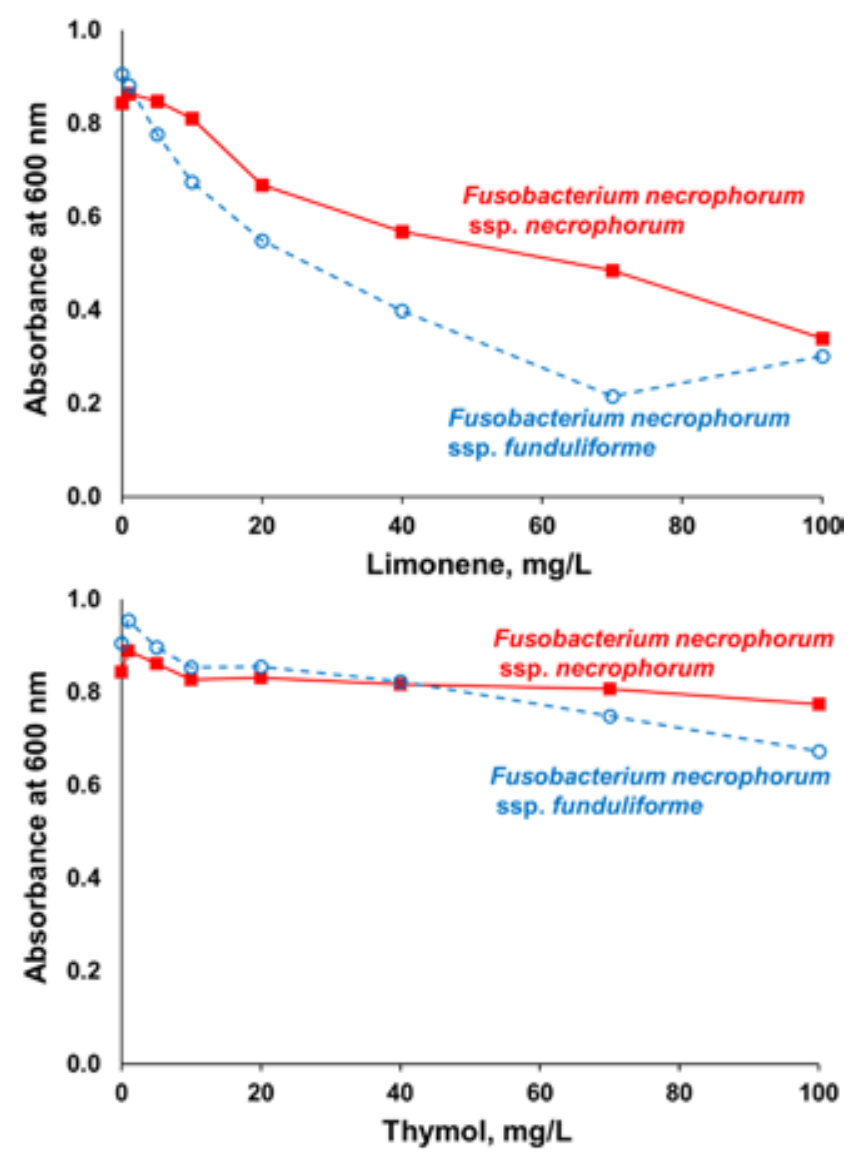

Figure 1. Effect of limonene and thymol on growth (absorbance at $600 \mathrm{~nm}$ ) of Fusobacterium necrophorum ssp. necrophorum (ם) and $F$. necrophorum ssp. funduliforme ( $($ ) in vitro at $24 \mathrm{~h}$ (Exp. 1). SEM $=0.14$. Linear and quadratic effects of limonene $(P<0.001)$ and linear effects of thymol $(P<0.01)$ were present. Effects of subspecies $(P=0.50)$ and treatment $\times$ subspecies $(P=0.51)$ were not detected.

growth, with the rate of decrease in absorbance at 600 $\mathrm{nm}$ being greater at low concentrations of limonene than at high concentrations of limonene. The contrast for subspecies $\times$ quadratic effect of limonene was evident $(P=$ 0.02 ) as growth of FNsF was less than that for FNsN at $70 \mathrm{mg} / \mathrm{L}$ limonene, but it was similar between FNsN and FNsF when $100 \mathrm{mg} / \mathrm{L}$ limonene was provided.

Thymol inclusion in the culture medium led to linear $(P=0.002)$ decreases in FN growth, and the response to thymol was similar between FNsN and FNsF $(P \geq 0.13)$. Although thymol did decrease FN growth, limonene was more effective than thymol $(P<0.0001$; Fig. 1$)$. The decreases in FN growth in response to limonene in vitro were large enough to suggest that limonene could be an effective agent for decreasing ruminal FN concentrations. Elwakeel et al. (2013) observed that limonene at 20 or $100 \mathrm{mg} / \mathrm{L}$ strongly reduced 24-h growth of FN, whereas $20 \mathrm{mg} / \mathrm{L}$ of thymol did not reduce growth of FN but 100 $\mathrm{mg} / \mathrm{L}$ of thymol did. Thus, there is similarity between the studies in that limonene was more effective than thymol in reducing FN growth at concentrations of $20 \mathrm{mg} / \mathrm{L}$. However, in contrast to the results of the present experiment, 
Table 2. Effect of limonene and thymol combinations on growth ${ }^{1}$ of Fusobacterium necrophorum ssp. necrophorum and $F$. necrophorum ssp. funduliforme in vitro (Exp. 2) $)^{2}$

\begin{tabular}{lllccc}
\hline \hline $\begin{array}{l}\text { Thymol, } \\
\mathrm{mg} / \mathrm{L}\end{array}$ & 0 & 5 & 10 & 20 & \\
\cline { 2 - 5 } & 0.87 & 0.81 & 0.74 & 0.60 & 0.12 \\
\hline 0 & 0.88 & 0.80 & 0.72 & 0.59 & \\
5 & 0.84 & 0.78 & 0.74 & 0.57 & \\
10 & 0.84 & 0.75 & 0.65 & 0.52 & \\
20 & &
\end{tabular}

${ }^{1}$ Values in table are absorbance at $600 \mathrm{~nm}$ in cultures grown for $24 \mathrm{~h}$.

${ }^{2}$ Linear effect of thymol $(P=0.03)$. Linear effect of limonene $(P<$ $0.0001) . F$-test for thymol $\times$ limonene $(P=0.99) . F$-test for subspecies $\times$ thymol $\times$ limonene $(P=0.99)$.

Elwakeel et al. (2013) found that $20 \mathrm{mg} / \mathrm{L}$ of limonene or $100 \mathrm{mg} / \mathrm{L}$ of thymol led to nearly complete inhibition of FN growth, whereas the current study found somewhat more modest reductions in FN growth with the same concentrations of these essential oil components.

\section{Experiment 2: Interactions between Limonene and Thymol on In Vitro Growth of FN}

Limonene $(P<0.0001)$ and thymol $(P=0.03)$ linearly decreased growth of FN in vitro. However, for concentrations of limonene and thymol up to $20 \mathrm{mg} / \mathrm{L}$, there were no interactions between thymol and limonene $(P=$ 0.99; Table 2), and the subspecies $\times$ limonene $\times$ thymol interaction was similarly absent $(P=0.99)$. Elwakeel et al. (2013) observed that thymol at $20 \mathrm{mg} / \mathrm{L}$ was not effective in reducing FN growth, so no large response to thymol alone was expected. Importantly, the lack of a synergistic response between limonene and thymol was demonstrated here. Given that thymol was less effective than limonene in inhibiting the growth of FN (Exp. 1) and demonstrated no synergistic effects with limonene (Exp. 2), there appeared to be little benefit to further studying the effects of thymol on FN growth.

\section{Experiment 3: Effects of Limonene and Tylosin on In Vitro Growth of FN}

Both limonene and tylosin were effective in reducing growth of $\mathrm{FN}$, but the pattern across the range of concentrations as well as over time were different between the 2 compounds (Fig. 2). Tylosin demonstrated linear and quadratic effects on FN growth $(P<0.0001)$, with the quadratic response occurring because $12 \mathrm{mg} / \mathrm{L}$ of tylosin led to nearly complete inhibition of FN growth such that the greatest concentration of $24 \mathrm{mg} / \mathrm{L}$ had little opportunity to further decrease it. There were no interactions between tylosin concentration and FN subspecies $(P \geq 0.25)$, suggesting that tylosin was equally effective
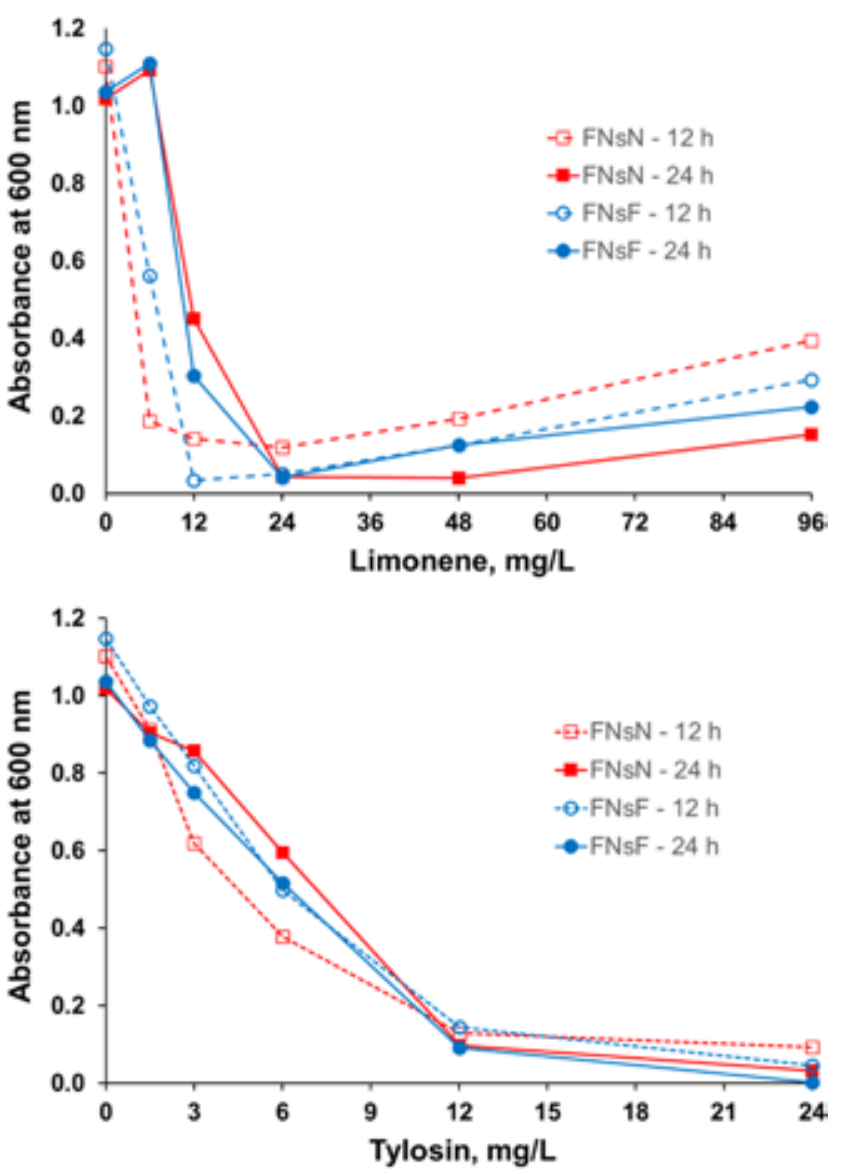

Figure 2. Effect of limonene and tylosin on growth (absorbance at 600 $\mathrm{nm}$ ) of Fusobacterium necrophorum ssp. necrophorum (FNsN; $\square$ at $12 \mathrm{~h}, \boldsymbol{\square}$ at 24 ) and F. necrophorum ssp. funduliforme (FNsF; $\circ$ at $12 \mathrm{~h}, \bullet$ at $24 \mathrm{~h}$ ) in vitro (Exp. 3). SEM $=0.053$. Linear, quadratic, and cubic effects of limonene and linear and quadratic effects of tylosin were evident $(P<0.0001)$. Treatment $\times$ time effects were also present $(P<0.0001)$ because the linear and cubic effects of limonene differed between 12 and $24 \mathrm{~h}$; limonene concentrations of 6 and 12 $\mathrm{mg} / \mathrm{L}$ were more effective in reducing FN growth at $12 \mathrm{~h}$ than at $24 \mathrm{~h}$, whereas this difference between times was not observed for greater concentrations of limonene. Main effect of subspecies was not present $(P=0.55)$. A treatment $\times$ subspecies $\times$ time effect was present $(P<0.01)$ because a large difference between subspecies was only observed for $6 \mathrm{mg} / \mathrm{L}$ limonene at $12 \mathrm{~h}$.

against FNsN and FNsF. The 3-way interactions involving tylosin, subspecies, and time also lacked significance. The ability of 12 and $24 \mathrm{mg} / \mathrm{L}$ of tylosin to inhibit FN growth by $89 \%$ and $96 \%$, respectively, is consistent with previous work that showed that tylosin inhibited growth of FN with an MIC of 10 to $25 \mathrm{mg} / \mathrm{L}$ (Tan et al., 1994a; Nagaraja et al., 1999a; Elwakeel et al., 2013), although smaller MIC of 0.03 to $2 \mathrm{mg}$ tylosin/L have also been demonstrated (Mateos et al., 1997).

The response of FN growth to limonene inclusion in the culture medium was much more complex than the response to tylosin. The overall response to limonene included linear, quadratic, and cubic components $(P<$ $0.0001)$, although the shape of the response to limonene was dependent on the time at which the growth was measured (12 vs. $24 \mathrm{~h}$ ) and to a lesser extent the subspecies of FN that was being tested. Treatment $\times$ time 
Table 3. Effect of dietary supplementation with limonene, CRINA-L, or tylosin on ruminal F. necrophorum concentrations and $\mathrm{pH}$ in heifers before feeding on $\mathrm{d} 4,7$, and 10 (Exp. 4)

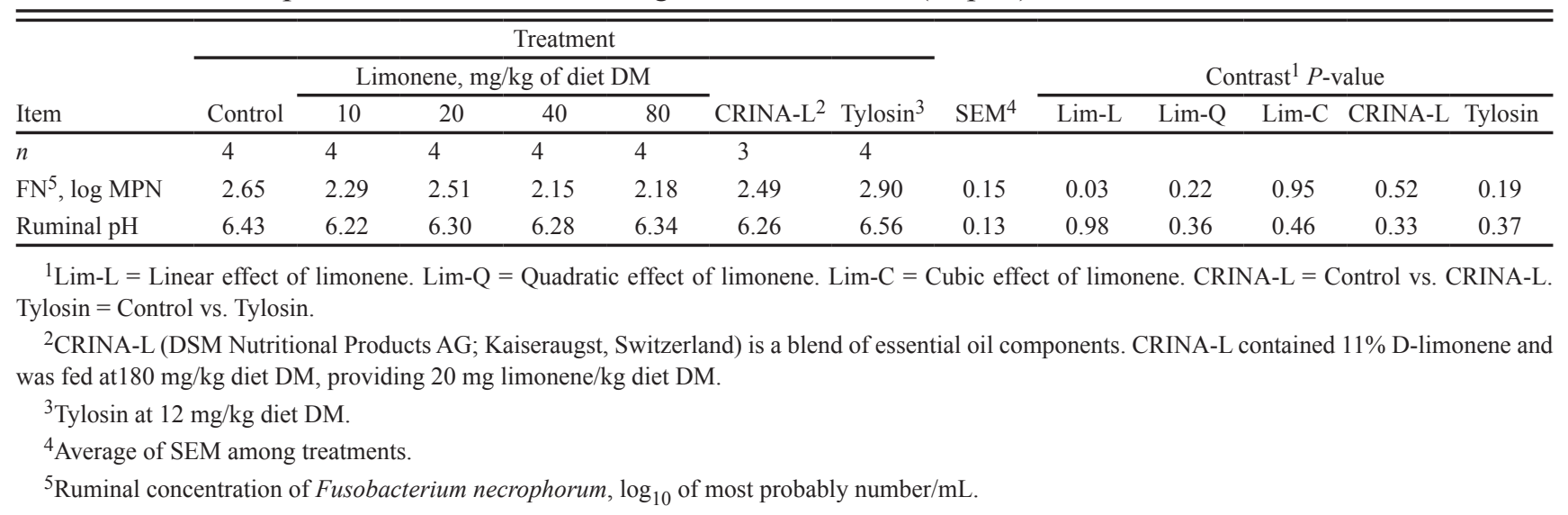

effects were present because the linear and cubic effects of limonene differed between 12 and $24 \mathrm{~h}(P<0.0001)$; limonene concentrations of 6 and $12 \mathrm{mg} / \mathrm{L}$ were more effective in reducing FN growth at $12 \mathrm{~h}$ than at $24 \mathrm{~h}$, whereas this difference between times was not observed for greater concentrations of limonene. A treatment $x$ subspecies $\times$ time effect was present $(P<0.01)$ because a large difference between subspecies was observed for $6 \mathrm{mg} / \mathrm{L}$ limonene at $12 \mathrm{~h}$ but not at other concentrations or times. In general, the differences between subspecies were not large and the overall pattern of response to limonene was similar between FNsN and FNsF.

When 6 or $12 \mathrm{mg} / \mathrm{L}$ of limonene was provided, growth at $12 \mathrm{~h}$ was less than growth at $24 \mathrm{~h}$, suggesting that these concentrations of limonene slowed the growth of FN, but, at least at the concentration of $6 \mathrm{mg} / \mathrm{L}$, did not decrease growth at $24 \mathrm{~h}$. The lowest growth of FN at $24 \mathrm{~h}$ was observed for $24 \mathrm{mg} / \mathrm{L}$ of limonene, but surprisingly the growth inhibition of limonene was somewhat less when 48 or $96 \mathrm{mg} / \mathrm{L}$ of limonene was provided.

At concentrations of $6 \mathrm{mg} / \mathrm{L}$, limonene led to numerically less FN growth at $12 \mathrm{~h}$ than did tylosin, although $6 \mathrm{mg} / \mathrm{L}$ of limonene was ineffective in decreasing FN growth at $24 \mathrm{~h}$. It is unknown how the slowing of FN growth might influence its concentration in the rumen, but slower growth would be expected to lower concentrations in a system such as the rumen with a continuous outflow of digesta.

The results in Exp. 3 showed limonene to be more effective in inhibiting growth of FN than was observed in Exp. 1, particularly at intermediate concentrations of limonene. These observations would more closely match the extent of inhibition observed by Elwakeel et al. (2013) than the modest reductions in Exp. 1. Although there was some suggestion in Exp. 1 that $100 \mathrm{mg} / \mathrm{L}$ of limonene was no more beneficial than $70 \mathrm{mg} / \mathrm{L}$, the apparently lower effect of $96 \mathrm{mg} / \mathrm{L}$ than of $24 \mathrm{mg} / \mathrm{L}$ in Exp. 3 is not consistent with Exp.
1 , even if only the $24-\mathrm{h}$ data are evaluated. There is no simple explanation for the different pattern of response to limonene at $24 \mathrm{~h}$, because the methods were essentially similar between Exp. 1 and Exp. 3 .

One goal of Exp. 3 was to provide a direct comparison of the effects of tylosin and limonene on FN growth. Previous research has demonstrated that tylosin is effective in decreasing FN growth, with an MIC of 10 to $25 \mathrm{mg} / \mathrm{L}$ (Tan et al., 1994a; Nagaraja et al., 1999a; Elwakeel et al., 2013). In contrast, Exp. 1 suggested that limonene only partly inhibited the growth of FN, although nearly complete inhibition of growth was observed with $20 \mathrm{mg} / \mathrm{L}$ of limonene by Elwakeel et al. (2013). Thus, we wanted to compare effects of tylosin and limonene at concentrations below the MIC, which is important because tylosin is known to reduce liver abscesses in cattle when fed in amounts that would likely yield ruminal concentrations less than the MIC. Despite this, we are unaware of data demonstrating the effect of tylosin on growth of FN when it is present in concentrations less than the MIC. Data from Exp. 3 demonstrated that limonene at concentrations achievable with a commercial product could be effective in inhibiting FN to extents similar to that achieved with tylosin.

At $12 \mathrm{~h}$, limonene and tylosin (at equal concentrations) had similar abilities to reduce the growth of FN. The very low growth of FN in the presence of 12 to $24 \mathrm{mg} / \mathrm{L}$ of tylosin is consistent with previously reported MIC. One interesting, but unexplainable, observation was that the highest concentrations of limonene (48 to $96 \mathrm{mg} / \mathrm{L}$ ) were less effective in inhibiting growth at $12 \mathrm{~h}$ than the intermediate concentrations of limonene (12 to $24 \mathrm{mg} / \mathrm{L}$ ).

At $24 \mathrm{~h}$, when compared at the same concentrations, tylosin was more effective in reducing the growth of FN than the limonene. This difference from the observations at $12 \mathrm{~h}$ might suggest that the FN was able to degrade the limonene over time or that the lim- 
Table 4. Effect of dietary supplementation with limonene, CRINA-L, or tylosin on ruminal $\mathrm{pH}, \mathrm{NH}_{3}, \alpha$-amino $\mathrm{N}$, peptide $\mathrm{N}$, and organic acids on $\mathrm{d} 10$ in heifers (Exp. 4) ${ }^{1}$

\begin{tabular}{|c|c|c|c|c|c|c|c|c|c|c|c|c|c|}
\hline \multirow[b]{3}{*}{ Item } & \multicolumn{7}{|c|}{ Treatment } & \multirow[b]{3}{*}{ SEM $^{5}$} & \multirow{2}{*}{\multicolumn{5}{|c|}{ Contrast $^{2} P$-value }} \\
\hline & \multirow[b]{2}{*}{ Control } & \multicolumn{4}{|c|}{ Limonene, $\mathrm{mg} / \mathrm{kg}$ of diet $\mathrm{DM}$} & \multirow[b]{2}{*}{ CRINA-L ${ }^{3}$} & \multirow[b]{2}{*}{ Tylosin 4} & & & & & & \\
\hline & & 10 & 20 & 40 & 80 & & & & Lim-L & Lim-Q & Lim-C & CRINA-L & Tylosin \\
\hline $\bar{n}$ & 4 & 4 & 4 & 4 & 4 & 3 & 4 & & & & & & \\
\hline $\mathrm{pH}$ & 6.06 & 6.06 & 6.34 & $\begin{array}{c}6.22 \\
\mathrm{~m} M\end{array}$ & 6.27 & 5.88 & 6.26 & 0.14 & 0.21 & 0.29 & 0.49 & 0.27 & 0.20 \\
\hline $\mathrm{NH}_{3}$ & 11.6 & 9.5 & 8.2 & 9.2 & 9.7 & 7.2 & 10.5 & 1.3 & 0.56 & 0.13 & 0.23 & 0.03 & 0.49 \\
\hline$\alpha$-amino $\mathrm{N}$ & 4.27 & 3.51 & 3.40 & 3.39 & 3.67 & 4.69 & 4.00 & 0.38 & 0.54 & 0.13 & 0.39 & 0.48 & 0.62 \\
\hline Peptide N & 6.41 & 5.45 & 5.41 & 5.53 & 5.87 & 6.60 & 6.51 & 0.49 & 0.81 & 0.15 & 0.29 & 0.78 & 0.88 \\
\hline Organic acids & 124 & 114 & 103 & $\begin{array}{c}114 \\
b 1 / 100\end{array}$ & 111 & 131 & 116 & 13 & 0.63 & 0.44 & 0.34 & 0.67 & 0.58 \\
\hline Acetate $^{6}$ & 54.3 & 58.8 & 58.9 & 57.7 & 59.1 & 53.3 & 59.2 & 2.0 & 0.25 & 0.38 & 0.14 & 0.73 & 0.08 \\
\hline Propionate & 25.9 & 21.6 & 16.9 & 20.2 & 17.7 & 26.8 & 16.8 & 2.5 & 0.07 & 0.18 & 0.10 & 0.80 & 0.02 \\
\hline Isobutyrate & 1.01 & 0.98 & 1.05 & 0.96 & 0.97 & 0.88 & 0.98 & 0.057 & 0.34 & 0.98 & 0.47 & 0.05 & 0.51 \\
\hline Butyrate & 11.6 & 11.3 & 14.0 & 13.0 & 13.4 & 13.1 & 15.1 & 0.84 & 0.10 & 0.19 & 0.57 & 0.23 & $<0.01$ \\
\hline 2-methyl butyrate & 4.36 & 4.73 & 6.51 & 5.95 & 6.41 & 3.54 & 5.36 & 0.76 & 0.07 & 0.23 & 0.45 & 0.48 & 0.35 \\
\hline 3-methyl butyrate & 1.07 & 1.05 & 1.02 & 0.98 & 0.97 & 0.79 & 0.96 & 0.062 & 0.14 & 0.43 & 0.84 & $\leq 0.01$ & 0.14 \\
\hline Valerate & 1.64 & 1.37 & 1.26 & 1.36 & 1.19 & 1.41 & 1.36 & 0.13 & 0.05 & 0.33 & 0.12 & 0.23 & 0.12 \\
\hline
\end{tabular}

${ }^{1}$ Values are average concentrations at 0,2, 4, 6, 8, and $10 \mathrm{~h}$ after feeding. Except for acetate, no treatment $\times$ hour interactions were observed.

${ }^{2} \mathrm{Lim}-\mathrm{L}=$ Linear effect of limonene. Lim-Q $=$ Quadratic effect of limonene. Lim-C = Cubic effect of limonene. CRINA-L = control vs. CRINA-L. Tylosin $=$ Control vs. Tylosin .

${ }^{3}$ CRINA-L (DSM Nutritional Products AG; Kaiseraugst, Switzerland) is a blend of essential oil components. CRINA-L contained 11\% D-limonene and was fed at $180 \mathrm{mg} / \mathrm{kg}$ diet DM, providing $20 \mathrm{mg}$ limonene $/ \mathrm{kg}$ diet DM.

${ }^{4}$ Tylosin at $12 \mathrm{mg} / \mathrm{kg}$ diet DM.

${ }^{5}$ Average of SEM among treatments.

${ }^{6}$ Treatment $\times$ hour interaction $(P=0.02$; data not shown).

onene did not maintain its inhibition over the longer period of time.

Taken as a whole, data from Exp. 3 suggest that limonene might be an effective agent to reduce ruminal concentrations of FN.

\section{Experiment 4: Effect of Limonene, Tylosin, and CRINA-L on In Vivo Ruminal Concentrations of FN, Fermentation, and Lysine Degradation}

There were no significant interactions between sampling day and treatment for MPN $(P=0.64$; data in Table 3$)$. The only significant interaction between time and treatment on d 10 (data in Table 4) was molar proportion of acetate $(P=0.02)$.

Effect of Limonene on Ruminal FN. Limonene linearly decreased $(P=0.03)$ ruminal FN concentrations ( $\log _{10}$ MPN; Table 3$)$. However, limonene did not have an effect on $\mathrm{pH}$ at time of sampling for FN measurements on $\mathrm{d} 4,7$, and 10 (Table 3 ). In our study, $40 \mathrm{mg} / \mathrm{kg}$ of limonene in the diet could be interpreted as the best concentration to reduce concentrations of FN in vivo. Assuming instantaneous mixing of limonene from the diet with ruminal liquid, no degradation or ruminal absorption of limonene, and first-order passage of limonene from the rumen at a rate equal to our observed average liquid passage rate (Table 5), the average ruminal concentration of limonene would be $6 \mathrm{mg} / \mathrm{L}$ for the treatment providing $40 \mathrm{mg} / \mathrm{kg}$ of limonene.

In the study reported by Elwakeel et al. (2013), limonene at concentrations of 20 or $100 \mathrm{mg} / \mathrm{L}$ inhibited growth of strains of FNsN and FNsF at $24 \mathrm{~h}$ and $48 \mathrm{~h}$ when grown in pure cultures in PRAS-BHI. Similarly, Exp. 1, 2, and 3 showed that limonene inhibited growth of FNsN and FNsF in PRAS-BHI, with decreases in growth with limonene concentrations as low as $6 \mathrm{mg} / \mathrm{L}$. In the work of Castillejos et al. (2006), limonene at 50 and $500 \mathrm{mg} / \mathrm{L}$ decreased in vitro $\mathrm{NH}_{3}$ production $(6 \%$ and $15 \%$, respectively), suggesting that limonene has a toxic effect on $\mathrm{NH}_{3}$-producing bacteria such as $\mathrm{FN}$.

This is the first in vivo study of limonene effects on ruminal FN concentrations, and further research on a larger scale will be needed to investigate the effect of limonene on FN and subsequently on liver abscesses. Although reductions in ruminal $\mathrm{FN}$ concentrations were observed in response to limonene, the magnitude of decrease may not be sufficient to affect prevalence of liver abscesses. Moreover, the populations of FN adherent to the ruminal wall may be more important in affecting liver abscess formation than $\mathrm{FN}$ in ruminal fluid (Narayanan et al., 1997). 
Table 5. Effect of dietary supplementation with limonene, CRINA-L, or tylosin on $\mathrm{NH}_{3}$, lysine degradation and disappearance rates, liquid passage rate, and rumen liquid volume on $\mathrm{d} 11$ in heifers following ruminal dosing of 30 g L-lysine (Exp. 4) ${ }^{1}$

\begin{tabular}{|c|c|c|c|c|c|c|c|c|c|c|c|c|c|}
\hline \multirow[b]{3}{*}{ Item } & \multicolumn{7}{|c|}{ Treatment } & \multirow{2}{*}{\multicolumn{6}{|c|}{ Contrast $^{2} P$-value }} \\
\hline & \multirow[b]{2}{*}{ Control } & \multicolumn{4}{|c|}{ Limonene, $\mathrm{mg} / \mathrm{kg}$ of diet $\mathrm{DM}$} & \multirow[b]{2}{*}{ CRINA-L ${ }^{3}$} & \multirow[b]{2}{*}{ Tylosin 4} & & & & & & \\
\hline & & 10 & 20 & 40 & 80 & & & $\mathrm{SEM}^{5}$ & $\overline{\text { Lim-L }}$ & Lim-Q & Lim-C & CRINA-L & Tylosin \\
\hline $\bar{n}$ & 4 & 4 & 4 & 4 & 4 & 3 & 4 & & & & & & \\
\hline $\mathrm{NH}_{3}, \mathrm{~m} M$ & 9.8 & 9.7 & 9.7 & 10.0 & 9.3 & 9.3 & 11.2 & 1.1 & 0.62 & 0.79 & 0.71 & 0.63 & 0.36 \\
\hline Lysine disappearance rate, $\mathrm{h}^{-1}$ & 0.264 & 0.266 & 0.232 & 0.244 & 0.218 & 0.234 & 0.285 & 0.023 & 0.14 & 0.82 & 0.68 & 0.40 & 0.53 \\
\hline Liquid passage rate, $\mathrm{h}^{-1}$ & 0.055 & 0.052 & 0.045 & 0.057 & 0.034 & 0.038 & 0.073 & 0.012 & 0.26 & 0.58 & 0.40 & 0.35 & 0.27 \\
\hline Lysine degradation rate, $\mathrm{h}^{-1}$ & 0.210 & 0.215 & 0.187 & 0.186 & 0.184 & 0.195 & 0.211 & 0.025 & 0.39 & 0.62 & 0.96 & 0.70 & 0.97 \\
\hline Rumen volume, L & 23.0 & 26.4 & 25.7 & 23.4 & 27.0 & 24.2 & 20.8 & 2.8 & 0.50 & 0.82 & 0.24 & 0.77 & 0.54 \\
\hline
\end{tabular}

${ }^{1}$ Samples were collected at $3,6,9$, and $12 \mathrm{~h}$ after dosing.

${ }^{2}$ Lim-L $=$ Linear effect of limonene. Lim-Q $=$ Quadratic effect of limonene. Lim-C $=$ Cubic effect of limonene. CRINA-L $=$ Control vs. CRINA-L. Tylosin $=$ Control vs. Tylosin

${ }^{3}$ CRINA-L (DSM Nutritional Products AG; Kaiseraugst, Switzerland) is a blend of essential oil components. CRINA-L contained 11\% D-limonene and was fed at $180 \mathrm{mg} / \mathrm{kg}$ diet DM, providing $20 \mathrm{mg}$ limonene $/ \mathrm{kg}$ diet DM.

${ }^{4}$ Tylosin at $12 \mathrm{mg} / \mathrm{kg}$ diet DM.

${ }^{5}$ Average of SEM among treatments.

Effect of Limonene on Ruminal Fermentation. On d 10, limonene tended to linearly reduce $(P \leq 0.07)$ molar proportions of propionate and valerate, whereas it tended to linearly increase $(P \leq 0.10)$ molar proportions of butyrate and 2-methyl butyrate (Table 4). However, limonene had no effect on $\mathrm{pH}(P \geq 0.21)$ or concentrations of $\mathrm{NH}_{3}(P \geq 0.13)$, peptide $\mathrm{N}(P \geq 0.15), \alpha$-amino $\mathrm{N}(P \geq 0.13)$, or total organic acids $(P \geq 0.34)$. Molar proportions of acetate $(P \geq 0.14)$, isobutyrate $(P \geq 0.34)$, and 3-methyl butyrate $(P \geq 0.14)$ in ruminal fluid were not affected by limonene (Table 4). In general, the shifts in fermentation end-products in response to limonene supplementation were modest, but likely reflective of some shifts in microbial populations.

Effects of Limonene on Ruminal Lysine Degradation. On d 11, limonene did not have any effect on $\mathrm{NH}_{3}$ concentrations $(P \geq 0.62)$, lysine degradation rate $(P \geq 0.39)$, lysine disappearance rate $(P \geq 0.14)$, liquid passage rate $(P \geq 0.26)$, or rumen liquid volume $(P \geq 0.24$; Table 5). F. necrophorum is known to be a primary lysine degrading bacteria, which can utilize lysine as a sole energy source while producing $\mathrm{NH}_{3}$, acetate, and butyrate (Gharbia and Shah, 1989; Russell, 2006; Nagaraja and Lechtenberg, 2007; Elwakeel et al., 2013). In our study, although limonene reduced FN concentrations in the rumen, it did not affect lysine degradation rate (d 11) or $\mathrm{NH}_{3}$ concentration (d 10 or d 11). We hypothesized that by inhibiting growth of $\mathrm{FN}$, lysine degradation rate would be reduced, which consequently might decrease $\mathrm{NH}_{3}$ production and ruminal concentrations; however, this effect was not evident. In agreement, Elwakeel et al. (2013) studied the effect of adding FN to mixed ruminal cultures supplemented with lysine, and they found no increase in lysine degradation as measured by $\mathrm{NH}_{3}$ production. Explanations might include that 1) reductions in FN were not large enough to affect lysine degradation, 2) FN may not be the primary lysine-degrading bacteria, or 3) other lysine-fermenting bacteria may compensate when FN are decreased by limonene.

Effect of Tylosin on Ruminal FN. Tylosin had no effect on concentrations of FN (Table 3). Numerous studies have demonstrated that tylosin reduces prevalence of liver abscesses, increases feed efficiency, and increases weight gain (Brown et al., 1975; Potter et al., 1985; Vogel and Laudert, 1994). The reduction of liver abscesses is related to the reduction of FN concentrations in the rumen and liver (Nagaraja et al., 1996), and the mode of action of tylosin is to inhibit protein synthesis within bacteria (Tan et al., 1994a). In our study, tylosin surprisingly led to numerical increases in FN. Furthermore, our results do not match with findings of Elwakeel et al. (2013) and of Exp. 3, where tylosin was effective in inhibiting growth of both $\mathrm{FNsN}$ and $\mathrm{FNsF}$ in vitro. One explanation for these differences might be that FN in our cattle were resistant to tylosin. However, this theory would not be supported by Nagaraja et al. (1999a), who investigated the susceptibilities of bacterial flora of liver abscesses to tylosin; their results did not show any resistance of FN to tylosin.

Effect of Tylosin on Ruminal Fermentation. On d 10, tylosin increased the ruminal molar proportions of butyrate $(P<0.01)$ and tended to increase $(P=0.08)$ acetate proportions. Propionate proportions were reduced by tylosin $(P=0.02)$. Tylosin did not affect $\mathrm{pH}(P=0.20)$, or concentrations of $\mathrm{NH}_{3}(P=$ $0.49)$, peptide N $(P=0.88), \alpha$-amino N $(P=0.62)$, or total organic acids $(P=0.58)$. Molar proportions of 
isobutyrate $(P=0.51), 2$-methyl butyrate $(P=0.35)$, 3 -methyl butyrate $(P=0.14)$, and valerate $(P=0.12)$ in ruminal fluid were not affected by tylosin (Table 4$)$. Although Nagaraja et al. (1999b) observed that tylosin decreased FN in steers fed a concentrate-based diet, they observed no effects of tylosin on ruminal fermentation products. However, Nagaraja et al. (1987) demonstrated with in vitro ruminal fermentations that tylosin reduced lactate production from glucose.

Effect of Tylosin on Ruminal Lysine Degradation. On d 11, tylosin did not affect $(P \geq 0.27) \mathrm{NH}_{3}$ concentrations, lysine degradation rate, lysine disappearance rate, liquid passage rate, or rumen liquid volume (Table 5). Because tylosin did not reduce FN concentrations, the lack of effect on lysine degradation is not surprising.

Effect of CRINA-L on Ruminal FN. Concentrations of $\mathrm{FN}$ and ruminal $\mathrm{pH}$ at time of sampling were not affected by CRINA-L $(P=0.33$; Table 3$)$.

Effect of CRINA-L on Ruminal Fermentation. On d 10, CRINA-L reduced $(P=0.03) \mathrm{NH}_{3}$ concentrations (Table 5). CRINA-L also decreased both isobutyrate $(P=0.05)$ and 3 -methyl butyrate $(P<0.01)$ proportions (Table 5). CRINA-L did not affect $\mathrm{pH}(P=0.27)$ or concentrations of peptide $\mathrm{N}(P=0.78), \alpha$-amino $\mathrm{N}(P=$ $0.48)$, total organic acids $(P=0.67)$. Molar proportions of acetate $(P=0.73)$, propionate $(P=0.80)$, butyrate $(P=0.23), 2$-methyl butyrate $(P=0.48)$, and valerate $(P=0.23)$ in the rumen were not affected by CRINA-L.

Effect of CRINA-L on Ruminal Lysine Degradation. On d 11, CRINA-L had no effect on $\mathrm{NH}_{3}$ concentrations $(P=0.63)$, lysine degradation rate $(P=0.70)$, lysine disappearance rate $(P=0.40)$, liquid passage rate $(P=0.35)$, or rumen liquid volume $(P=0.77$; Table 5$)$.

Essential oil components, especially those with terpenoid and phenolic structures, have shown antimicrobial activity (Dorman and Deans, 2000). Some essential oil components are active against a wide range of bacteria, particularly Gram-negative bacteria (Calsamiglia et al., 2007). Essential oils can inhibit the growth of bacteria by disintegrating the cell membrane (Helander et al., 1998; Dorman and Deans, 2000). The mode of action of terpenoid compounds has been attributed to the effect of isoprene units on cell membranes to inhibit electron and protein transport, phosphorylation reactions, and other chemical reactions; these effects are related to the lipid characteristics and solubility of terpenoids in the phospholipid bilayer of the cell membrane (Dorman and Deans, 2000).

The mode of action of essential oils with phenolic structures, such as thymol and carvacrol, is related to reduction of intracellular ATP of Gram-negative bacteria, leading to destruction of cell membrane activity (Helander et al., 1998). Furthermore, essential oils can inhibit bacterial growth through inhibition of RNA and DNA synthesis (Calsamiglia et al., 2007).
CRINA Ruminants (DSM Nutritional Products, Basel, Switzerland) is a commercial blend of essential oils containing thymol, guaiacol, eugenol, vanillin, and limonene. CRINA-L is a new product of the same company containing extra limonene (11\%). Meyer et al. (2009) reported that CRINA Ruminants tended $(P=0.08)$ to reduce total liver abscesses. McIntosh et al. (2003) studied the effect of CRINA Ruminants product in dairy cattle and suggested that the blend of essential oil compounds could decrease $\mathrm{NH}_{3}$ production by hyperammonia producing bacteria. Attwood et al. (1998) classified FN as a hyperammonia producing bacteria, and therefore we hypothesized that CRINA products might be able to inhibit growth of FN. However, CRINA failed to inhibit FN in vitro, probably because concentrations of limonene in the mixture of essential oil components were too low (Elwakeel et al., 2013). Of the 5 essential oil components found in CRINA Ruminants, only limonene at 20 or $100 \mathrm{mg} / \mathrm{L}$ and thymol at $100 \mathrm{mg} / \mathrm{L}$ were effective in inhibiting growth of FN in vitro (Elwakeel et al., 2013).

In our study, CRINA-L provided $20 \mathrm{mg}$ limonene/ $\mathrm{kg}$ DM, but responses were different between the CRINA-L and $20 \mathrm{mg} / \mathrm{kg}$ limonene treatments; CRINA-L did not reduce ruminal prevalence of $\mathrm{FN}$, whereas limonene by itself did decrease ruminal $\mathrm{FN}$ concentrations. On d 10, CRINA-L reduced $\mathrm{NH}_{3}$ concentration compared to control $(P=0.03)$, which might be related to inhibition of ammonia-producing bacteria. In addition, this mixture of essential oil components reduced isobutyrate and 3-methyl butyrate concentrations, suggesting decreased catabolism of AA within the rumen. Our data suggest that these responses to CRINA-L may have been mediated by components of the mixture besides limonene because similar results were not obtained by limonene alone. Similar to limonene alone, CRINA-L did not affect rate of lysine degradation on d 11. Overall, CRINAL should be considered as a rumen modifier, but little research has been conducted to study the effect of CRINA in feedlot conditions, and no research is available on the effects of CRINA-L. Therefore, further research would be needed to further clarify effects of this blend on animal performance or liver abscess incidence.

\section{Conclusions}

Our results demonstrate that limonene was effective in reducing ruminal concentrations of $\mathrm{FN}$ in vivo, suggesting that it might be effective in reducing liver abscesses in feedlot conditions. This research is the first in vivo experiment with limonene supplementation to cattle, and further research will be beneficial to determine the effect of limonene on a larger scale. 


\section{LITERATURE CITED}

Attwood, G. T., A. V. Klieve, D. Ouwerkerk, and B. K. C. Patel. 1998. Ammonia-hyperproducing bacteria from New Zealand ruminants. Appl. Environ. Microbiol. 64:1796-1804.

Binnerts, W. T., A. T. Van't Klooster, and A. M. Frens. 1968. Soluble chromium indicator measured by atomic absorption in digestion experiments. Vet. Rec. 82:470.

Broderick, G. A., and J. H. Kang. 1980. Automated simultaneous determination of ammonia and total amino acids in ruminal fluid and in vitro media. J. Dairy Sci. 63:64-75.

Brown, H., R. F. Bing, H. P. Grueter, J. W. McAskill, C. O. Cooley, and R. P. Rathmacher. 1975. Tylosin and chlortetracycline for the prevention of liver abscesses, improved weight gains and feed efficiency in feedlot cattle. J. Anim. Sci. 40:207-213.

Calsamiglia, S., M. Busquet, P. W. Cardozo, L. Castillejos, and A. Ferret. 2007. Invited review: Essential oils as modifiers of rumen microbial fermentation. J. Dairy Sci. 90:2580-2595

Castillejos, L., S. Calsamiglia, and A. Ferret. 2006. Effect of essential oil active compounds on rumen microbial fermentation and nutrient flow in in vitro systems. J. Dairy Sci. 89:2649-2658.

Dorman, H. J. D., and S. G. Deans. 2000. Antimicrobial agents from plants: Antibacterial activity of plant volatile oils. J. Appl. Microbiol. 88:308-316

Elwakeel, E. A., R. G. Amachawadi, A. M. Nour, M. E. A. Nasser, T. G. Nagaraja, and E. C. Titgemeyer. 2013. In: vitro degradation of lysine by ruminal fluid-based fermentations and by Fusobacterium necrophorum. J. Dairy Sci. 96:495-505

Gharbia, S. E., and H. N. Shah. 1989. The uptake of amino acids from a chemically defined medium by Fusobacterium species. Curr. Microbiol. 18:189-193.

Helander, I. M., H. L. Alakomi, K. Latva-Kala, T. Mattila-Sandholm, I. Pol, E. J. Smid, L. G. M. Gorris, and A. V. Wright. 1998. Characterization of the action of selected essential oil components on gram-negative bacteria. J. Agric. Food Chem. 46:3590-3595.

Ives, S. E., E. C. Titgemeyer, T. G. Nagaraja, A. del Barrio, D. J. Bindel, and L. C. Hollis. 2002. Effects of virginiamycin and monensin plus tylosin on ruminal protein metabolism in steers fed corn-based finishing diets with or without wet corn gluten feed. J. Anim. Sci. 80:3005-3015.

Jensen, R., H. M. Deane, L. J. Cooper, V. A. Miller, and W. R. Graham. 1954. The rumenitis-liver abscess complex in beef cattle. Am. J. Vet. Res. 15:202-216.

Mateos, E., S. Piriz, J. Valle, M. Hurtado, and S. Vadillo. 1997. Minimum inhibitory concentrations for selected antimicrobial agents against Fusobacterium necrophorum isolated from hepatic abscesses in cattle and sheep. J. Vet. Pharmacol. Ther. 20:21-23.

McIntosh, F. M., P. Williams, R. Losa, R. J. Wallace, D. A. Beever, and C. J. Newbold. 2003. Effects of essential oils on ruminal microorganisms and their protein metabolism. Appl. Environ. Microbiol. 69:5011-5014.

Merchen, N. R. 1988. Digestion, absorption and excretion in ruminants. In: D. C. Church, editor, The ruminant animal (Digestive physiology and nutrition). Prentice Hall, Englewood Cliffs, NJ. p. 172-201.
Meyer, N. F., G. E. Erickson, T. J. Klopfenstein, M. A. Greenquist, M. K. Luebbe, P. Williams, and M. A. Engstrom. 2009. Effect of essential oils, tylosin, and monensin on finishing steer performance, carcass characteristics, liver abscesses, ruminal fermentation, and digestibility. J. Anim. Sci. 87:2346-2354.

Nagaraja, T. G., A. B. Beharka, M. M. Chengappa, L. H. Carroll, A. P. Raun, S. B. Laudert, and J. C. Parrott. 1999a. Bacterial flora of liver abscesses in feedlot cattle fed tylosin or no tylosin. J. Anim. Sci. 77:973-978.

Nagaraja, T. G., S. B. Laudert, and J. C. Parrott. 1996. Liver abscesses in feedlot cattle. Part I. Causes, pathogenesis, pathology and diagnosis. Compend. Contin. Educ. Pract. Vet. 18:5230-5241.

Nagaraja, T. G., and K. F. Lechtenberg. 2007. Liver abscesses in feedlot cattle. Vet. Clin. North Am. Food Anim. Pract. 23:351-369

Nagaraja, T. G., Y. Sun, N. Wallace, K. E. Kemp, and C. J. Parrott. 1999b. Effects of tylosin on concentrations of Fusobacterium necrophorum and fermentation products in the rumen of cattle fed a high-concentrate diet. Am. J. Vet. Res. 60:1061-1065.

Nagaraja, T. G., M. B. Taylor, D. L. Harmon, and J. E. Boyer. 1987. In: vitro lactic acid inhibition and alterations in volatile fatty acid production by antimicrobial feed additives. J. Anim. Sci. 65:1064-1076.

Narayanan, S. K., T. G. Nagaraja, O. Okwumabua, J. Staats, M. M. Chengappa, and R. D. Oberst. 1997. Ribotyping to compare Fusobacterium necrophorum isolates from bovine liver abscesses, ruminal walls, and ruminal contents. Appl. Environ. Microbiol. 63:4671-4678.

Palmer, D. W., and T. Peters, Jr. 1969. Automated determination of free amino groups in serum and plasma using 2, 4, 6-trinitrobenzene sulfonate. Clin. Chem. 15:891-901.

Potter, E. L., M. I. Wray, R. D. Muller, H. P. Grueter, J. McAskill, and D. C. Young. 1985. Effect of monensin and tylosin on average daily gain, feed efficiency and liver abscess incidence in feedlot cattle. J. Anim. Sci. 61:1058-1065.

Russell, J. B. 2006. Factors affecting lysine degradation by ruminal fusobacteria. FEMS Microbiol. Ecol. 56:18-24

Scanlan, C. M., and T. L. Hathcock. 1983. Bovine rumenitisliver abscess complex: A bacteriological review. Cornell Vet. 73:288-297.

Tadepalli, S., S. K. Narayanan, G. C. Stewart, M. M. Chengappa, and T. G. Nagaraja. 2009. Fusobacterium necrophorum: A ruminal bacterium that invades liver to cause abscesses in cattle. Anaerobe 15:36-43

Tan, Z. L., T. G. Nagaraja, and M. M. Chengappa. 1994a. Biochemical and biological characterization of ruminal Fusobacterium necrophorum. FEMS Microbiol. Lett. 120:81-86.

Tan, Z. L., T. G. Nagaraja, and M. M. Chengappa. 1994b. Selective enumeration of Fusobacterium necrophorum from the bovine rumen. Appl. Environ. Microbiol. 60:1387-1389.

Vogel, G. J., and S. B. Laudert. 1994. The influence of tylan on liver abscess control and animal performance. A 40 trial summary. J. Anim. Sci. 72(Suppl. 1):293. (Abstr.). 